\title{
Research on the mechanism of cross regional grassland carbon sink compensation
}

\author{
CHEN Lan \\ School of International business \\ Inner Mongolia University of Technology, \\ City of Hohhot, Inner Mongolia, China, 010080 \\ Email:175984753@qq.com
}

\author{
MA Jun \\ School of International business \\ Inner Mongolia University of Technology, \\ City of Hohhot, Inner Mongolia, China, 010080 \\ Email: majun@imut.edu.cn \\ Corresponding author
}

\begin{abstract}
Nowadays, grassland ecological environment is increasingly deteriorated, and grassland management process is emerging new problems. The paper is based on the economic theory, and use the forest carbon compensation experience as reference, puts forward a cross regional grassland carbon compensation mechanism theory, which is firstly based on the government and secondly based on the market. This theory can solve the interest conflict problem made by administrative regionalism.
\end{abstract}

Keywords-Across the region, Compensation mechanism, Grassland carbon sink

\section{INTRODUCTION}

In recent years, ecological compensation has become one of the important factors in the ecological economy and ecological protection, and the grassland carbon sink compensation plays an important role as an important part of ecological compensation. But at present, the grassland carbon sink sequestration in our country is still in the initial stage, which still has big development space in the compensation mechanism of grassland and cross regional grassland carbon sink compensation. For the grassland is public belonging property and it has very typical external features, there will inevitably be friction and cooperation among the regions in the grassland management. Therefore, it is very important to establish the effective compensation mechanism of grassland carbon sink compensation.

Research in China has not specifically targeted at the cross regional grassland carbon sink compensation, but reflected in some individual areas of cross regional ecological compensation, mainly concentrated on the cross regional watershed compensation, cross regional mineral resources development and compensation, cross regional air compensation and such aspects. Specifically, firstly, the study of the western ecological compensation; secondly, the compensation of the air in the north of Beijing. HE Biao (2014) believes that the administrative division fragmented the environment protection, which is bad to the increasingly urgent situation of ecological environment. There will be some problems on such as regional interest conflict and ecological environment management issues, therefore, to establish coordinated regional relations that reflects social justice is imperative; WANG Yi (2011) thought that the trans-area ecological compensation is a trade that pay the fee of machine service on ecological management, which provides services for two or more administrative boundaries that have same goal. He believes in that the most important problem being solved in cross regional compensation is equity issues, instead of the issue of efficiency. In this foundation, we can focus the grassland carbon sink compensation mechanism research on the government policy and measures of the government.

In our country, the division of the administrative region is very clear, but the ecological system can't simply be divided into the political area, therefore, there is an urgent need for the regional carbon compensation. In addition, under the situation of the increasingly worsen environmental problem, the measures of the government in environmental protection, governance and resource utilization will become increasingly prominent, while in the same time China doesn't has clear measure to solve and coordinate grassland carbon sink compensation. Therefore, in order to improve the efficiency of grassland management, and to plan co-ordination of grassland carbon sink compensation between the areas as a whole, the study of cross regional grassland carbon sink compensation is more urgent. 


\section{II.DEMAND ANALYSIS OF CROSS REGIONAL}

\section{GRASSLAND CARBON SINK SEQUESTRATION}

In recent years, China has invested more than before in environmental compensation, and compensation has become an important measure to coordinate economic development and ecological protection. However, the existing researches of China's grassland carbon sink compensation mechanism have no clear concept of how to set a effective mechanism to manage the compensation of the cross regional grassland, meanwhile the national compensation measures are not specifically targeted, only existing some individual local measures which few related to the cross regional grassland ecological compensation mechanism, so that the development of cross regional grassland carbon sink compensation mechanism has become a top priority, which can be discussed from two aspects.

\section{A. The Common Interests Between The regions}

The grassland carbon sink compensation between regions is established between two or more administrative regions which hold common grassland carbon sink compensation target, which is a exchange of cost on service provided to solve the grassland carbon sink problems. The common needs and objectives of grassland carbon sink compensation are the premise of the regional cooperation. Holding similar economic compensation level of grassland carbon sink is essential to achieve specific compensation objectives among regions. From the perspective, the establishment of service levels can not only be decided by region's own demand, but also needs to consider the demand of inter regional cooperation in the whole. In consideration of the characteristics of cross regional compensation, the characteristics of grassland can not be ignored in the design of carbon compensation mechanism.

First of all, for the external characteristics of grassland, the destruction of grassland may not undertake only by one region or organization, the pollution should be shared by different regions and organization. In the same way, the consequences that caused by policies and actions of one government may be undertake by other places and people. Therefore, the interests of many parties should be taken into account in the study of the grassland carbon sink compensation mechanism, only the interests of different stakeholders are concerned, the co-support and smooth implementation can be gained. The grassland carbon sink compensation mechanism can survive and develop smoothly.

Secondly, taking the political nature of the cross regional compensation into account. In order to coordinate the compensation problem among regions, it needs to formulate a clear national policy and law to restrict the behavior of the parties, and reduce the conflicts of interest among the regions. So the formulation of the grassland carbon sink compensation mechanism should take administrative, legal, scientific and technological factors into account to find a more coordinated approach that ensure the governance keep a long time. From this point of view, in the formulation and implementation process, we must thinking about the existing trend such as the division of policy, fragmentation, decent realization. At the same time, we should take the private sector and the organization of the volunteer consultation into account, to Improve the cooperation efficiency between government and market.

\section{B. Cross-region Net Overflow In Compensation}

From the division of administrative regions in China, there are many common interests between adjacent regions, which are the basis of regional peace and development. Therefore, the key to solve the problem is to establish a compensation mechanism that different regions can make benefit from or reduce the cost. It is not only based on grassland carbon sink compensation in a certain area, but also to provide more cross region net spillover including more services. The so-called grassland compensation net spillover is belong to the area that holds grassland carbon sink compensation service, and the amount is that grassland carbon sink compensation service outflow volume minus the amount of the inflow volume ${ }^{[2]}$. That is to say, the grassland carbon sink compensation in the region is a compensation for the net spillover, and not simply to provide full compensation for all regions. That is to say, the net inflow of ecological services should compensate for the area of the net outflow, in order to achieve the purpose of regional balanced 
development, improving the efficiency of grassland carbon sink sequestration management.

In the development of grassland carbon sink compensation in China, a lot of regions only attach importance to regional outflow, while ignoring the overall grassland ecological development problems. In this condition, the grassland's public characteristics must be referred to. As a representative product of the public property, grassland is not only a provincial area but also involves the natural factors of air, water and soil. Therefore, the compensation for the grassland carbon sink is not just any one department, organization or government can control or governance, it needs different departments on varied levels of government to collaborate with each other.

\section{THE ANALYSIS FOR CONSTRAINTS OF CROSS REGIONAL GRASSLAND CARBON SINK COMPENSATION}

\section{A. Inter-regional Coordination of Interests}

The interest coordination is the key to the regional compensation. The government is the most fundamental and essential power in the management of cross regional cooperation. Only the regional governments find common interest that cooperation can be found in the trans-regional cooperation. That is to say, the grassland carbon sink compensation is a process of negotiate and compromise on conflict between the regions. Specifically, cross regional carbon compensation will involve two aspects of the interests.

\section{1) Interest compensation}

At present, the grassland damage is serious, causing a lot of constraints in the development of carbon sinks trade. The government emphasizes GDP and neglects environmental problems all the time, so in order to improve the speed of GDP rising, even at the expense of destroying the grassland environment. And carbon sink compensation as a part of the financial expenditure is excluded from government development projects. Therefore, in the development of grassland carbon sink compensation, it is bound to take some measures in the grassland management process to adjust the economic development structure of grassland areas, which maybe reduce the development rate of GDP. This will directly damage the interests of the government, from this point of view, the central to the local, or local to the place, the different level of government should address some certain compensation to the loss parties.

\section{2) Cost sharing in compensation}

At this stage, the governments are not willing to make a further consultation on the cost of compensation. The regional characteristics of the trans-regional grassland carbon sink compensation includes the cross administrative boundaries, cross functional boundaries and cross time boundaries. In particular, the cross administrative boundaries are determined by the existing administrative region of our country. ${ }^{[3]}$ Firstly, if we want to compensate the cross regional carbon sink, we need a number of intergovernmental mutual cooperation, including mutual consultation between the governments at the same level and policy and financial support between different levels of government. Secondly, the growth of grassland involving the air, water, land and other factors, therefore the grassland carbon sink compensation should take the interests of many parties into account. Finally, considering the influence of time, the grassland's growth cycle decides manage cycle, so the time of grassland can't be ignored in the process of compensation.

\section{B. Benefit Control Problems Of Main Compensation body}

Accurate positioning the government, market and society in the role of carbon compensation can improve the efficiency of cross regional grassland carbon sink compensation. Nowadays China, government is still the single center of compensation model, that is to say, the government undertakes the main financial expenditure. The central government allocated money to local governments, local governments allocated money to the specific projects. However, the government only plays an effective role in some areas, but only can play a very limited role in compensation, especially in the area where market and social participation is not active. Most of the time, the compensation can not meet the requirements of the cross regional grassland carbon sink compensation, therefore market mechanism is needed to intervene to reduce the pressure of the government. The market has no division, so the market compensation can make up the lack of the government management, to a 
certain extent, can bring positive benefits to the government, and produce the net spillover in government compensation.

\section{CROSS REGIONAL GRASSLAND CARBON SINK COMPENSATION MECHANISM}

At present, China doesn't have a sound mechanism in the cross-regional grassland carbon compensation, but it has been reflected in ecological compensation. Even so, in these areas also practice government-oriented model, the role of the market is rarely reflected. Therefore, from this point of view, the structure of establishment of the cross regional grassland carbon compensation mechanism both containing the government and the market is shown in Table 1. However, in this paper, we pay more attention to the versatility of compensation. So we not only strength the importance of government, but also pay more attention to the market that can adjust industrial structure of grassland, in which way to combine market and social forces to make them become the main manage resources outside the financial system. In this paper, we expound in three ways, the main types of compensation, content of compensation, and measures of compensation:

\section{A. Compensation For Government}

1)Cross regional compensation of grassland damage

The local governments have to strengthen cooperation and develop unified compensation standards to make up the loss that grassland damage makes to the herdsmen and factories in surrounding areas. There is a big difference between the areas of grassland management policy, a sound measures of a regional planning will directly affect grassland area management, and produce the positive external influence, and vice verse. However, most of the grassland in China is underdeveloped, make they to take the cost of compensation by themselves is very difficult. Then, how we define the direction and standards of cost compensation depends largely on the clear degree of property rights. Such as Zhangjiakou and Beijing in the problem of water treatment, in Zhangjiakou, due to the unreasonable use of water, it has a bad impact on water resources utilization in
Beijing, therefore, Beijing requires Zhangjiakou to manage water resources. However, Zhangjiakou's governance funds are jointly undertaken by both sides, Beijing makes certain compensation on Zhangjiakou's governance results. Specific form of environmental protection can be to set special fiscal funds[4], to establish a cross regional compensation for special expenses, tax on the organization damaging grassland, establish specialized cross-regional grassland compensation fund. Cross regional areas should be in the case of the consultation to put the funds into a unified account, and set a special department to manage.

2)Service compensation of cross regional grassland ecosystem

If we want to realize the service compensation of grassland ecosystem, we must set the full price of the cost of grassland ecological environment. In China's vast grassland areas, the government and people are in a very awkward position, because the current grassland carbon sink price system is not integrated, the environmental management and environmental compensation of the grassland area is rely on the local government. The government can only have mandatory means to set the enterprises in this area to control the damage or make compensation. This mandatory makes companies can't continue to operate. However, if the government is added to the process of compensation, the pressure in ecological environment management of enterprise can remit, the cross region of grassland carbon sink compensation will promote the common development of the two regions.

\section{B. Regional Compensation For Market Participation}

\section{1) Trading of regional emission right}

At present, it is a common phenomenon that the regional economic development of grassland is lagging behind, and it is very difficult to realize the transaction of emissions. However, the emission right transaction must be one of the premise of market participation in regional compensation, China's grassland has a lot of polluting enterprises, to manage these enterprises on the grassland need a long period. So if we want to achieve emissions trading, firstly should fixed the pollution sources, in order to be able to accurately and 
continuously measure the amount of pollutants according to specific standards, and charge the corresponding costs. In this period, if the enterprise improve their technical to reduce their emissions, the government can be given certain compensation to the enterprise based on the amount of pollution emissions reduction, in return, the government should be charged higher fees to motivate enterprises to improve their technology.

\section{2) Grassland ecological zone construction}

At present, the main ecological zones of China are in the forest, reservoir, and the establishment of grassland ecological zone has great development space, but in the trans regional grassland, the conflict between governments is becoming increasingly fierce. The important reason is that our current assessment system, the region as an independent individual tend to protect their own convenience, to pass the compensation costs to their neighbor. Therefore, to overcome this problem, it can establish grassland ecological zones in the boundary area, to unified standards of governance and compensation. And at the same time, to give the region a certain preferential conditions, the one who develops a project to promote the development of this region will gain the higher standards of compensation. In this way it's easy to coordinate inter regional grassland policy, overcome the fragmentation caused by the division of the regional development.

Chart 1: Mechanism design of cross regional grassland carbon compensation

\section{CONCLUSIONS}

In a word, combining various cross regional grassland carbon sink compensation method to form an effective compensation system, and promoting the sustainable development of grassland ecology in trans regional is necessary. No matter what kind of cross regional grassland carbon sink compensation method, can not ignore to strength the cooperation between the market and the government. As the emphasis on environmental issues in Beijing, to play down the impact of the administrative region, we need to establish a full and effective communication platform and an equal and effective communication mechanism to properly resolve the external nature of the grassland, to balance interests of different regions. This compensation mechanism can be led by the government and guide the market to participate in, also the government can be a rule-maker, add the market to the main body of the compensation model.

\section{ACKNOWLEDGMENT}

This research was financially supported by the National Science Foundation of China under Grant No.71363039.

\section{REFERENCES}

[1] J. Meng Hongqi, Xu Huashan. The establishment of cross regional resources allocation and rejuvenation compensation system. The ecological environment of February 2010

[2] J. Wang Yu, analysis of cross regional ecological services and compensation theory. The search of 2011 (6)

[3] J Wang Weiquan, cross regional cooperative governance of air pollution -- a case study of in Beijing area, 2014 (1)

[4] J Chang Liang, Xu Dawei, Hou Tieshan, Yang Chunwei, inter regional ecological compensation inter regional coordination mechanism research. Science and technology and management , 3013 (1)

[5] Chen Chaomei. CiteSpace II : Detecting and visualizing emerging trends and transient patterns in scientific literature[J]. JAm Soc InfSci Technol, 2006,(03):359-377.

[6] Ecosystem Marketplace, Forest Trends. State of the Forest Carbon Markets 2011: $\quad$ From Canopy toCurrency[EB/OL].[2011-09-29].http://www.Forestcarbonportal.co m/resource/state-forest-carbon-markets-2011-canopy-currency.

[7] Benitez P,McCallum I,Obersteiner M,et al.Global Supply for Carbon Sequestration: Identifying Least-Cost Afforestation Sites Under Country Risk Considerations[R]. Laxenburg, Austria,IIASA IR-04-022,2004. 